\title{
Serum immunoglobulins to endotoxin core glycolipid: acute leukaemia and other cancers
}

\author{
S K Jackson, J Parton, G Shortland, J M Stark, E N Thompson
}

\begin{abstract}
Circulating antibody to endotoxin core glycolipid and total serum immunoglobulin concentrations were measured in 86 children with cancer (54 with acute lymphoblastic leukaemia, four with acute myeloid leukaemia, and 28 with various solid tumours). Measurements were made before treatment in the group with acute lymphoblastic leukaemia as well as when patients were both on and off chemotherapy. In the other two groups measurements were made when patients were both on and off treatment. Significant reductions in endotoxin antibody and serum immunoglobulin concentrations were found only in patients with acute lymphoblastic leukaemia. In addition, there was a significant correlation between febrile episodes and the concentration of antibody to core glycolipid in the children with acute lymphoblastic leukaemia. These findings suggest that the use of prophylactic high titre endotoxin antibody may be of benefit to children with life threatening Gram negative infections who are receiving cytotoxic chemotherapy.
\end{abstract}

Infective complications during optimum treatment of childhood cancer have become increasingly common, contributing appreciably to morbidity and mortality. Haematological cancers are associated with a higher incidence of infection than solid tumours, partly as a consequence of the intensity of treatment with subsequent granulocytopenia. ${ }^{1}$ Although Gram positive organisms are important pathogens in these patients, Gram negative organisms are usually responsible for the life threatening infections that carry such a high mortality. ${ }^{2-4}$ Fulminating Gram negative infections often develop despite adequate antibiotic and supportive care. ${ }^{5}$ Though antibiotic resistance and the underlying clinical condition may contribute to the severity of the infective episode, other variables such as the presence of bacterial endotoxin and protective naturally occurring endotoxin antibody may be important. High titres of normal antibody to endotoxin core glycolipid have been associated with enhanced survival from Gram negative septicaemia in surgical, ${ }^{6}$ gynaecological, and obstetric patients. ${ }^{7}$ In addition, recent trials of purified immunoglobulins containing antilipopolysaccharide antibody in patients suffering from septic shock have shown them to be beneficial. ${ }^{8}$ Passive immunotherapy in these critically ill patients may therefore be helpful.

The present study was designed to document naturally occurring circulating antibody to endotoxin core glycolipid in children with acute leukaemia and other cancers, in stable and febrile phases, both on and off treatment. The aim was to determine if prophylactic high titre antiendotoxin immunoglobulin treatment might have a place in the treatment of fulminating infection in high risk patients receiving cytotoxic chemotherapy.

\section{Patients and methods}

Eighty six children with cancer (acute lymphoblastic leukaemia, $n=54$; acute myeloid leukaemia, $n=4$, solid tumours, $n=28$ ) were studied. Fifty three of them were tested more than once, both during treatment and up to two years after all chemotherapy had been discontinued. Fourteen children with acute lymphoblastic leukaemia were tested before treatment was started, 17 were tested in the first 12 weeks of treatment, 26 were tested later during the two years of maintenance chemotherapy, and 23 were tested after all chemotherapy had been discontinued (3-24 months off treatment). All children were in remission except the 14 in the group tested before treatment. Children with acute myeloid leukaemia and solid tumours were tested after treatment had been started.

Twenty six febrile episodes were documented during this study period. Blood was obtained at the time of bacteriological investigation for antiendotoxin core glycolipid concentrations.

Control serum samples were obtained from 94 children aged 6 months to 16 years (mean age 6.2 years). These children were either siblings of the leukaemic children, attenders at hospital for non-infective problems, or being admitted for elective operations. No child had samples taken specifically for this study, but blood obtained at the time other investigations were being done was used. Full parental consent was obtained.

\section{BLOOD SAMPLES}

Routine blood samples for serum antibody measurements were taken where possible before treatment, and on three other occasions (during the first 12 weeks, during maintenance, and at least three months after treatment had been discontinued).

Anti core glycolipid antibody was measured by an enzyme linked immunoadsorbent assay (ELISA), ${ }^{9}$ and total IgG, IgM, and IgA were determined by radial immunodiffusion. 
Table 1 Immunoglobulin concentrations in children with acute myeloid leukaemia and solid tumours compared with normal controls without malignant disease. Results are given as mean (2 SD) of logged values

\begin{tabular}{|c|c|c|c|}
\hline & $\begin{array}{l}\text { Control } \\
(n=94)\end{array}$ & $\begin{array}{l}\text { Acute } \\
\text { myeloid leukaemia } \\
(n=4)\end{array}$ & $\begin{array}{l}\text { Solid tumour } \\
(n=28)\end{array}$ \\
\hline $\begin{array}{l}\text { Anticore glycolipid IgG (\%) } \\
\text { Anticore glycolipid IgM (\%) } \\
\text { Total IgG (g/l) } \\
\text { Total IgA (g/l) } \\
\text { Total IgM (g/l) }\end{array}$ & $\begin{array}{l}1.103(0.775) \\
1.879(0.85) \\
1.050(0.53) \\
0.100(0.74) \\
0.042(0.64)\end{array}$ & $\begin{array}{c}1.142(0.65) \\
1.586(1.05)^{*} \\
1.278(0.38)^{*} \\
0.297(0.43)^{*} \\
-0.002(0.46)\end{array}$ & $\begin{array}{l}1.108(0.73) \\
1.705(0 \cdot 73)^{*:} \\
1.218(0 \cdot 40)^{*: *} \\
0.208(0.43)^{: *} \\
-0.044(0.55)\end{array}$ \\
\hline
\end{tabular}

${ }^{*} \mathrm{p}<0.05$, and ${ }^{* *} \mathrm{p}<0.005$ compared with controls.

Table 2 Changes in antiendotoxin core glycolipid IgG and total serum immunoglobulin with treatment in children with acute lymphoblastic leukaemia. Results are expressed as mean (2SD) of logged values. Subjects were studied more than once as they moved among treatment groups

\begin{tabular}{|c|c|c|c|c|c|}
\hline \multirow[t]{2}{*}{ Stage of treatment } & \multirow{2}{*}{$\begin{array}{l}\text { No of } \\
\text { subjects }\end{array}$} & \multirow{2}{*}{$\begin{array}{l}\text { Anticore } \\
\text { glycolipid IgG }\end{array}$} & \multicolumn{3}{|c|}{ Total immunoglobulins $(\mathrm{g} / \mathrm{l})$} \\
\hline & & & $\overline{I g G}$ & $\operatorname{Ig} A$ & $I g M$ \\
\hline $\begin{array}{l}\text { Controls } \\
\text { Before treatment } \\
\text { Induction } \\
\text { Maintenance } \\
\text { No treatment }\end{array}$ & $\begin{array}{l}94 \\
14 \\
17 \\
26 \\
23\end{array}$ & $\begin{array}{l}1 \cdot 103(0 \cdot 77) \\
0.938(0.60) \\
0.942(0 \cdot 70) \\
0.855(0 \cdot 50) \\
1.144(0.52)\end{array}$ & $\begin{array}{l}1.050(0.53) \\
1.031(0.44) \\
0.972(0.47) \\
0.917(0.47) \\
1.253(0.29)\end{array}$ & $\begin{array}{c}0.100(0.74) \\
-0.95(0.64) \\
-0.110(0.72)^{*} \\
-0.266(0.74)^{*} \\
0.235(0.38)^{:}\end{array}$ & $\begin{array}{c}0.042(0.64) \\
-0.114(0.94) \\
-0.392(0.84)^{*} \\
-0.300(0.84)^{*} \\
0.090(0.44)\end{array}$ \\
\hline
\end{tabular}

* $\mathrm{p}<0.05$ and ** $\mathrm{p}<0.005$, compared with controls.

\section{Results}

Results of the total immunoglobulin concentrations together with specific antiendotoxin core glycolipid immunoglobulin in patients with acute myeloid leukaemia and solid tumours are shown in table 1 . The results for children with acute lymphoblastic leukaemia at different stages of treatment are shown in table 2. All data are presented as means (2 SD) of $\log _{10}$ antibody titres. Table 1 shows that in patients with acute myeloid leukaemia and solid tumours there is a significant reduction only in titres of anti core glycolipid IgM antibody when compared with age matched controls.

Table 2 shows that concentrations of all immunoglobulins tested in patients with acute lymphoblastic leukaemia were lower than those of the age matched controls. This decrease was significant during maintenance treatment.

The effect of stage in treatment of acute lymphoblastic leukaemia is also shown in table 2. The mean age of the groups increased slightly as treatment progressed but this did not significantly affect any differences in immunoglobulin measurements among the groups. ${ }^{9}$ The difference in mean anti core glycolipid titre between the measurements before treatment and those in the control group was appreciable, but not significant. A significant fall in anti core glycolipid occurred during maintenance treatment, with restoration to normal once the child was off treatment.

Concentration of total immunoglobulins varied with the stage of treatment; serum $\operatorname{IgA}$ was significantly lower before treatment. During induction treatment serum IgA and IgM concentrations were reduced, with a significant reduction in all three antibody classes in the maintenance phase. As with the anti core glycolipid antibody, immunoglobulin concentrations returned to normal when chemotherapy had stopped.

ASSOCIATION OF FEBRILE EPISODES WITH ANTI CORE GLYCOLIPID TITRE

Febrile episodes (temperature $>38^{\circ} \mathrm{C}$ on more

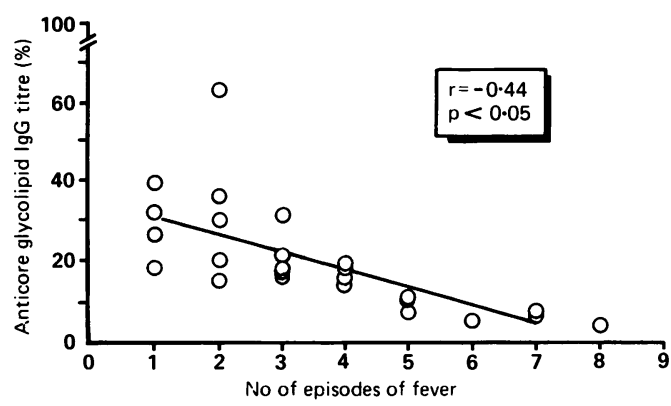

Association of initial anti core glycolipid IgG titre with number of episodes of fever experienced during treatment.

than two consecutive occasions) were documented for all children undergoing treatment for acute lymphoblastic leukaemia. The figure shows the association between the number of febrile episodes and the initial anti core glycolipid antibody titre: there was a significant inverse correlation $(r=-0.44 ; p<0.05)$. Five children had proved Gram negative infections and two had Gram positive infections during the study. One patient developed fatal Escherichia coli meningitis, and one patient developed shock after septicaemia from an $E$ coli strain and survived. Most $(80 \%)$ of the febrile episodes did not correlate with positive blood cultures.

\section{Discussion}

In recent years aggressive treatment has greatly improved the prognosis for children suffering from most of the childhood cancers. ${ }^{10}$ Intensification of treatment has, however, been associated with a pronounced increase in life threatening infections. Although granulocytopenia remains the single most important risk factor in patients on chemotherapy, other mechanisms in immune defence may be important. ${ }^{11}$

The results of this study have shown that children with acute lymphoblastic leukaemia on chemotherapy have reduced titres of specific anti core glycolipid antibody compared with normal age matched controls. This deficit in 
specific anti core glycolipid antibody was not present in children suffering from acute myeloid leukaemia or solid tumours. Furthermore, total IgG concentrations were not significantly reduced in children with acute lymphoblastic leukaemia, suggesting that the reduction in specific antibody was not a reflection of the total immunoglobulin concentrations.

Children with acute lymphoblastic leukaemia are more at risk from infection when they are in remission, independent of the degree of granulocytopenia, in contrast to children with acute myeloid leukaemia and other cancers. ${ }^{12}{ }^{13}$ This, combined with the knowledge that children with acute lymphoblastic leukaemia have reduced titres of anti core glycolipid antibodies, suggests a possibly beneficial role for passive immunisation with antisera to core glycolipid.

Children with acute lymphoblastic leukaemia had reduced anti core glycolipid antibody titres before the start of treatment. The titres of this antibody fell further during treatment, but recovered to normal values when treatment was discontinued. The underlying disease might cause a decrease in antibody production by bone marrow infiltration, ${ }^{14}$ while cytotoxic treatment would produce defects in the cell mediated immune response. ${ }^{15}$ Our results suggest that these children have an impaired antibody response and were not less exposed to infection in view of the age of the children and the positive titres to lipopolysaccharide core glycolipid found in normal children over the age of 2 years. ${ }^{16}$

Low initial anti core glycolipid antibody titres correlated with an increased incidence in febrile episodes. This supports the view that fever in the presence of negative bacteriological culture in these patients may be due to systemic endotoxins, ${ }^{17}$ and that specific antiendotoxin (core glycolipid) antibodies might reduce the effects of such endotoxaemias.

The results of our study support the concept of the prophylactic use of specific anti core glycolipid antisera in leukaemia patients, particularly those with acute lymphoblastic leukaemia. Trials using passive immunisation of patients with this type of antisera have been carried out in other groups of patients. ${ }^{18}$ Although it is too early to reach a definite conclusion from their results, it seems that such treatment can reduce the mortality from Gram negative infections. Recent evidence suggests that purified immunoglobulin $G$ prepared from normal blood donors with high concentrations of antilipopolysaccharide IgG reduces mortality from septic shock. ${ }^{19}$ The efficiency of such preparations indicates that it is not obligatory to develop antilipopolysaccharide monoclonal antibodies.

Our results suggest that children with acute lymphoblastic leukaemia - because of their lack of specific anti core glycolipid antibodies-may be more at risk from Gram negative infective complications than children with other leukaemias, or other cancers. This study has shown that immune treatment with specific high titre antisera may be of particular value in this group of patients.

1 Miser JS, Miser AW, Bleyer WA, et al. Septicemia in childhood malignancy. Analysis of 101 consecutive episodes. Clin Pediatr 1981;20:320-3.

2 Brown AE. Neutropenia fever and infection. Am 7 Med 1984;76:421-8.

3 Love LJ, Schimpff SC, Schiffer CA, Wiernik PH. Improved prognosis for granulocytopenic patients with gram negative prognosis for granulocytopenic patients

4 Singer C, Kaplan MH, Armstrong D. Bacteremia and fungemia complicating neoplastic disease: study of 364 fungemia complicating neoplastic

5 Bryan CS, Reynolds KL, Brenner ER. Analysis of 1,186 episodes of gram-negative bacteraemia in non-university hospitals: the effects of antimicrobial therapy. Rev Infec Dis 1983;5:629-38.

6 Freeman R, Gould FK. Prevention of fever and Gramnegative infection after open heart surgery by antiendotoxin Thorax 1985;40:846-8.

7 Lachman E, Pitso SB, Gaffin SL. Anti-lips immunotherapy in the management of septic shock of obstetrical and gynaecological origin. Lancet 1984;i:981-3.

8 Zeigler EJ, McCutchan JA, Fierer J, et al. Treatment of gram-negative bacteremia and shock with human antiserum to a mutant Escherichia coli. $N$ Engl f Med 1982;307:1225-30

9 Jackson SK, Parton J, Shortland G, Stark JM, Thompson EN. Serum immunoglobulins to endotoxin core glycolipid: EN. Serum immunoglobulins to endotoxin core glycolipid: 1990;65:768-70.

10 Anonymous. Better results in childhood leukaemia [Editorial] BrMed F 1973;ii:624-5.

11 Bodey GP, Buckley M, Sathe YS, Freireich EJ. Quantitative relationship between circulating leucocytes and infection in patients with acute leukaemia. Ann Intern Med 1966;64: $328-40$.

12 Hughes WT. Fatal infections in childhood leukaemia. $A m \mathfrak{f}$ Dis Child 1971;122:283-6.

13 Chessells JM, Leiper AD. Infection during remission induction in childhood leukaemia. Arch Dis Child 1980;55: 118-23.

14 Albano EA, Pizzo PA. Infectious complications in childhood acute leukaemias. Pediatr Clin North Am 1988;5:873-901.

15 Campbell AC, Hersey P, Maclennan ICM, et al. Immunosuppressive consequences of radiotherapy and chemotherapy in patients with acute lymphoblastic leukaemia. $B$ Med $\mathcal{F}$ 1973;ii:385-8.

16 Law BJ, Marks MI. Age related prevalence of human IgG and IgM antibody to the core glycolipid of Escherichia col strain J5, as measured by ELISA. $\mathcal{F}$ Infect Dis 1985;151 988-94.

17 McCartney AC, Robertson MRI, Piotrowicz BI, Lucie NP. Endotoxaemia, fever and clinical status in immunosup pressed patients: a preliminary study. $\mathcal{F}$ Infect 1987;15: 201-6.

18 Cohen J. Anti-endotoxin immunotherapy in septic shock. F Antimicrob Chemother 1984;145:231-6.

19 Fomsgaard AM, Baek L, Fomsgaard JS, et al. Preliminary study on treatment of septic shock patients with anti lipopolysaccharide IgG from blood donors. Scand F Infect Dis 1989;21:697-708. 